\title{
Diagnosis and Management of Common Hand Infections.
}

Vivek K. Bilolikar

Thomas Jefferson University

Daniel A Seigerman

Rothman Orthopaedic Institute

Asif M. Ilyas

Rothman Orthopaedic Institute

Follow this and additional works at: https://jdc.jefferson.edu/rothman_institute

Part of the Orthopedics Commons

Let us know how access to this document benefits you

\section{Recommended Citation}

Bilolikar, Vivek K.; Seigerman, Daniel A; and Ilyas, Asif M., "Diagnosis and Management of Common Hand Infections." (2020). Rothman Institute Faculty Papers. Paper 123.

https://jdc.jefferson.edu/rothman_institute/123

This Article is brought to you for free and open access by the Jefferson Digital Commons. The Jefferson Digital Commons is a service of Thomas Jefferson University's Center for Teaching and Learning (CTL). The Commons is a showcase for Jefferson books and journals, peer-reviewed scholarly publications, unique historical collections from the University archives, and teaching tools. The Jefferson Digital Commons allows researchers and interested readers anywhere in the world to learn about and keep up to date with Jefferson scholarship. This article has been accepted for inclusion in Rothman Institute Faculty Papers by an authorized administrator of the Jefferson Digital Commons. For more information, please contact: JeffersonDigitalCommons@jefferson.edu. 
Funding: No

OA: No

Article Type: Review Article

doi:10.2106/JBJS.RVW.19.00188

\section{Diagnosis and Management of Common Hand Infections}

Vivek K. Bilolikar, BS1, Daniel A. Seigerman, MD2, and Asif M. Ilyas, MD1,3 ISidney Kimmel Medical College at Thomas Jefferson University, Philadelphia, Pennsylvania 2Rothman Orthopaedic Institute, New York, NY

3Rothman Orthopaedic Institute, Philadelphia, Pennsylvania

Email address for V.K. Bilolikar: Vivek.k.bilolikar@gmail.com

ORCID iD for V.K. Bilolikar: 0000-0001-6818-4705

ORCID iD for D.A. Seigerman: 0000-0003-1317-2242

ORCID iD for A.M. Ilyas: 0000-0002-5636-9873

Investigation performed at Thomas Jefferson University and Rothman Orthopaedic Institute, Philadelphia, Pennsylvania

Disclosure: The authors indicated that no external funding was received for any aspect of this work. The Disclosure of Potential Conflicts of Interest forms are provided with the online version of the article (http://links.lww.com/XXXXXXX).

Hand \& Wrist 
Publication: JBJS Reviews

Type: Review Article; Volume: ; Issue:

Abstract

$>$ While many hand infections are superficial, diligent evaluation, diagnosis, and treatment of these infections are central for preventing disability and morbidity.

$>$ Maintaining a wide differential diagnosis is important as some hand infections may mimic others.

$>$ In geographic areas with more than a $10 \%$ to $15 \%$ prevalence of community-acquired methicillin-resistant Staphylococcus aureus (MRSA) hand infections, empiric antibiotics should adequately cover MRSA.

$>$ Once culture results are available, antibiotic regimens should be narrowed to reduce the development of resistant pathogens. 
Publication: JBJS Reviews

Type: Review Article; Volume: ; Issue:

Infections of the hand and fingers are common and benefit from prompt evaluation. While many infections may be self-limited and superficial, timely and effective treatment can prevent disability and morbidity, including loss of function, deformity, and the need for amputation/salvage procedures1-9. Effective treatment requires accurate diagnosis, appropriate antibiotics, and potential surgical intervention. The purpose of this article is to review the recent literature regarding the management of hand infections.

\section{Microbiology}

Skin flora are the most common causative agents of hand infections (Table I), specifically Staphylococcus and Streptococcus species3,8,10-13. The majority of the Staphylococcus species infections are caused by methicillin-sensitive Staphylococcus aureus (MSSA); however, the prevalence of methicillin-resistant $S$. aureus (MRSA)12-15 is growing. Over the past decade, empiric antibiotic treatment strategies have been adjusted to accommodate for evolving microbial resistance patterns. Although Kistler et al.14 identified a decreasing trend of MRSA hand infections at an urban academic center, the overall rate of MRSA hand infections remained high at $47 \%$ to $52 \% 12,13$. Tosti et al.13 identified increasing multidrug resistance patterns among hand infections over a 7-year period (2005 to 2012). It is important to be aware of the local flora and resistance patterns in order to appropriately treat hand infections 11,15-20.

\section{Antibiotic Therapy}

Table I provides recommendations for empiric antibiotic therapy for the various hand infections that are discussed below. The regimen should be adjusted as the specific pathogens are identified, in order to reduce the development of resistant pathogens and more effectively treat the specific pathogen. Traditionally, first-generation cephalosporins have been recommended for empiric antibiotic treatment. However, the Centers for Disease Control and Prevention recommend that in geographic regions where the prevalence of community-acquired MRSA infections is more than $10 \%$ to $15 \% 21$ (most urban and suburban regions), 
Publication: JBJS Reviews

Type: Review Article; Volume: ; Issue:

antibiotics that cover MRSA should be the first-line empiric treatment (e.g., trimethoprim/sulfamethoxazole, clindamycin, and doxycycline). For inpatients, intravenous vancomycin and clindamycin remain the drugs of choice22,23; however, recent publications report an increased prevalence of clindamycin-resistant MRSA (7\% in 2005 and 20\% in 2012)10,13,23,24.

\section{Patient Factors}

Patient factors that should be considered when managing hand infections are immunosuppression and intravenous drug use (IVDU). Immunosuppression predisposes patients to infection. The etiology of the suppressed state may vary with different conditions (e.g., human immunodeficiency virus (HIV)/acquired immunodeficiency syndrome (AIDS), diabetes mellitus (DM), or rheumatologic conditions, and in patients who use immunomodulating medications). While immunocompromised patients are more likely to become infected with common pathogens than immunocompetent individuals, they are also at an increased risk of opportunistic and nosocomial infections2,3,8,10,11,15-18,25. Additionally, they are more likely to have complications and may require more rounds of treatment compared with immunocompetent individuals2,3,8,10,11,15-18,25.

IVDU is linked to a higher rate of infections due to direct seeding of tissues (nonsterile injection practices or contaminated drugs), risk of HIV/AIDS, and riskier behaviors (sexual behaviors, poor hygiene, tissue trauma, or malnutrition)26,27. These infections are primarily due to $S$. aureus and polymicrobial infections $3,8,10,11,15-18,26,27$. The increasing rates of MRSA must be accounted for when treating hand infections that are linked to IVDU because these patients are more likely to have positive cultures after successful incision and drainage 10. IV drug abusers are also at a higher risk of nosocomial infections, necrotizing fasciitis, and gram-negative infections2,3,8,10,11,15-18,26,27.

\section{Paronychia}

Paronychia is the most common infection of the hand. It is an infection of the nail fold that is precipitated by a disruption of the seal between the 
Publication: JBJS Reviews

Type: Review Article; Volume: ; Issue:

nail plate and the paronychium/eponychium10,28.

Paronychia may present acutely (for $<6$ weeks) or chronically (for $>6$ weeks). The most common causes include nail injuries, onychophagia, manicures, and finger and/or thumb-sucking. The etiologies and treatments vary between acute and chronic paronychia.

\section{Acute Paronychia}

An acute paronychia typically presents with a painful erythematous nail fold, with possible fluctuance around the nail. The most common pathogens for acute paronychia are Staphylococcus, Streptococcus, Enterococcus, and Pseudomonas species29. Patients with an acute paronychia typically present with acute painful erythematous inflammation of the nail fold on a single digit30 (Fig. 1). Abscesses may form and disrupt the nail plate, causing elevation and onycholysis. Because the diagnosis is clinical, laboratory tests and imaging are not necessary28,30. Patient history should help rule out potential atypical organisms, such as herpes virus (see the section below on herpetic whitlow) and anaerobes (oral exposure) or gram-negative organisms (exposure to animals) 30 .

The management plan for acute paronychia depends on the extent of symptoms and/or the presence of an abscess. Early presentations with minimal to mild symptoms and without an abscess or cellulitis should be treated nonsurgically, which consists of empiric antibiotics (Table I) and frequent warm soaks28,30. Adding Burow's solution (aluminum acetate solution) and vinegar (acetic acid) to the warm soaks may have beneficial antimicrobial effects28,31. Topical corticosteroids are effective at managing symptoms with minimal to no side effects32. The presence of an abscess, extensive involvement of the eponychium, or unsuccessful nonsurgical management are indications for surgical management 28,30 .

\section{Chronic Paronychia}

Chronic paronychia refers to inflammation without fluctuance or abscess formation of the paronychium/eponychium that lasts for $>6$ weeks. Risk factors include repetitive exposure to irritants such as acids, alkali, and other chemicals, causing 
Publication: JBJS Reviews

Type: Review Article; Volume: ; Issue:

chronic inflammation that may precipitate colonization by bacterial or fungal pathogens (most commonly Candida albicans)28-30. Housekeepers, cooks, dishwashers, bartenders, laundry workers, and swimmers are at greater occupational risk of chronic paronychiaz8-30.

The initial step in management is to avoid irritants, moisture, and additional damage to the paronychium/eponychium (e.g., manicures or onychophagia)28-30. Medical management begins with controlling inflammation with topical corticosteroids, calcineurin inhibitors, antiinflammatory medications, or antifungals28,33 (Table I). Rigopoulos et al. found that $0.1 \%$ tacrolimus was more effective than $0.1 \%$ betamethasone in treating chronic paronychia34. Okano et al.35 and Merritt36 demonstrated that gentian violet dye (antiseptic and antifungal) also was effective at treating chronic paronychia. Associated bacterial infections can be managed with oral antibiotics (Table I). Systemic corticosteroids or antifungal agents are not necessary unless patients present with refractory disease or multidigit involvement28,30. For refractory cases, surgical intervention in the form of eponychial marsupialization, or nail excision without matrix ablation for cases with nail damage, may be indicated29,30,37.

Felon

A felon is a closed space infection of the pulp of the fingertip. Like a paronychia, it can be very painful, but unlike a paronychia it can advance quickly and generally does not involve the nail folds4,6,38. Typically, a felon develops after disruption of the skin barrier (e.g., fingertip glucose testing) and subsequent colonization4,5,38. Common pathogens are $S$. aureus followed by other Staphylococcus or Streptococcus species5. Felons may eventually spread, resulting in osteomyelitis of the distal aspect of the phalanx or septic flexor tenosynovitis4.

A felon is characterized by an acute onset of localized pain, erythema, swelling, and/or fluctuance of the distal digital pulp5,6. The pain is typically due to the buildup of pressure in the closed compartments of the digit4,5. Early presentations without abscess formation can be adequately treated 
Publication: JBJS Reviews

Type: Review Article; Volume: ; Issue:

with antibiotics (Table I), warm soaks, elevation, and observation 4,5,38. However, in the setting of fluctuance or an abscess, surgical drainage is indicated4-6,38. Typically, the incision is placed at the site of the greatest fluctuance. Whenever possible, a mid-lateral approach is recommended. Similarly, a radial-sided approach to the thumb and an ulnar-sided approach to the fingers are recommended to avoid incisions at the sites of key pinch. A "fish-mouth" incision is best avoided to prevent devascularization of the pulp and the skin. After the incision has been made, it is essential to take down all of the septa to adequately decompress and drain the pulp/compartment4-6. Following incision, drainage, taking of culture specimens, debridement of devitalized tissue, and thorough irrigation, the wound can be loosely closed or left open. Soaks can be initiated postoperatively, and empiric antibiotics should be administered (Table I) until wound culture specimens specify the pathogen and culture-specific antibiotics can be initiated $4,5,38$.

\section{Herpetic Whitlow}

Herpetic whitlow is a fingertip infection that is caused by the herpes simplex virus (HSV-1 or HSV-2). It is commonly mistaken for a felon or paronychia. The infection presents most commonly in a bimodal distribution in both children $(<10$ years old) and young adults (20 to 30 years old). It is spread via direct contact of infected bodily fluids and mucous membranes (including self-inoculation) with previously disrupted/irritated skin, making nail-biters, thumb-suckers, and dental professionals at highest risk39,40. Herpetic whitlow classically presents on the digital pulp as a single vesicle or a cluster of vesicles39,40. Vesicles are typically painful and have an area of central pallor on an erythematous base 39,41 . The lesions typically present 1 to 2 weeks after inoculation (which coincides with the window of viral shedding) 39,40 . Before the formation of the vesicles, patients may experience a flulike prodrome, consisting of fever and regional lymphadenitis39,40. Vesicles may coalesce and mimic another infection and/or abscess of the digit. Serologic studies are not used in the diagnosis of herpetic whitlow; however, a positive Tzanck test (specific for HSV and herpes zoster), viral culture, 
Publication: JBJS Reviews

Type: Review Article; Volume: ; Issue:

or polymerase chain reaction (PCR) study may be used to confirm the presence of HSV40. Herpetic whitlow in immunocompetent individuals is generally self-limited and resolves spontaneously within 3 weeks 39,41 . With recurrent or recalcitrant infections, acyclovir has been shown to be beneficial. Acyclovir is indicated for all immunocompromised patients who present with HSV, regardless of whether it is localized or disseminated 39,40 . Surgical treatment of herpetic whitlow is contraindicated as the risks of surgery outweigh the possible benefits39-41.

\section{Flexor Tenosynovitis}

Septic, suppurative, or pyogenic flexor tenosynovitis (FTS) is a closed space infection of the flexor tendon sheath. These infections are associated with substantial morbidity, including functional loss from stiffness, contracture, adhesions, and even loss of the finger and/or limb if not managed in a timely manner42-47. Even after appropriate and expeditious treatment, residual stiffness is commonplace. FTS makes up approximately $10 \%$ of hand infections; some studies report that the percentages are as high as $28.0 \%$ to $67.3 \% 3,8,10,17,43$. The most common pathogen is $S$. aureus (35\% to $75 \%$ of positive cultures), with the rate of MRSA being $14.4 \%$ to $29 \% 42,44-47$. Other common pathogens include Streptococcus species, Pseudomonas species, and other gram-negative organisms (these infections preferentially affect immunocompromised patients)42,44-47.

On physical examination, patients may exhibit Kanavel signs, including swelling of the digit, tenderness along the flexor tendon sheath, pain on passive extension of the finger, and a resting flexed position of the finger (Fig. 2)42,44-47. Only $54 \%$ of patients exhibit all 4 of these signs, which may be less discernible in the thumb and the fifth digit42,45,46. Studies attempting to validate the cardinal signs yielded mixed results: most experts agree that the combination of digital swelling and tenderness along the tendon sheath is highly indicative of FTS $42,45,46$. The detection of Kanavel signs in children is inconsistent, which may cause treatment delays45,46. Those with comorbidities may not exhibit Kanavel signs as dramatically as 
Publication: JBJS Reviews

Type: Review Article; Volume: ; Issue:

otherwise healthy individuals42. The diagnosis of FTS is clinical, and imaging is not needed.

Similarly, laboratory studies are nonspecific and are typically negative in the acute phase of FTS.

Treatment depends on the extent and the duration of symptoms. Healthy patients presenting with mild symptoms for $<48$ hours can be treated with empiric oral antibiotics (Table I) without surgical debridement42,45. DiPasquale et al., in a 12patient case series, found that nonoperative therapy (antibiotics, immobilization, elevation, and therapy) in patients with early FTS was effective, with a mean time to resolution of infective symptoms of 5 days ( 2 to 11 days)48. If symptoms worsen after trialing nonsurgical management, then surgical intervention is indicated. Surgical management involves irrigation of the tendon sheath and debridement. The 2 most common irrigation techniques are open irrigation and closed irrigation (continuous or intermittent). Open irrigation and debridement is the technique of choice to facilitate thorough drainage while also allowing for a tenosynovectomy, if necessary42,45. Empiric antibiotics (Table I) should be administered until operative culture specimens identify the pathogen and culture-specific antibiotics can be initiated. Using cadaveric models for FTS, Ketonis et al. found that $S$. aureus forms a biofilm on the flexor tendon, and surgical drainage and irrigation is inferior to mechanical debridement and local antibiotic placement with corticosteroid augmentation49. Based on these findings and in light of the flexor tendon's poor vascular supply, consideration should be given for thorough mechanical debridement of the flexor tendon and subsequent local antibiotic placement.

\section{Cellulitis}

Cellulitis is an infection of the skin that causes $>600,000$ hospitalizations every year in the United States of America50. Involvement of the hand is very common, with disruption of the skin barrier being the most common cause 5,51,52. $S$. aureus is the most common pathogen, followed by Streptococcus species5,11,15-20,50,51,53. The differential diagnosis includes other infections such as necrotizing fasciitis, varicella zoster, herpetic 
Publication: JBJS Reviews

Type: Review Article; Volume: ; Issue:

whitlow, and erythema migrans; inflammatory

conditions such as acute arthritis, gout, or bursitis;

and dermatologic conditions such as contact

dermatitis, hypersensitivity reaction, fixed drug

reaction, and venous stasis disease 50.

Cellulitis typically presents as a unilateral diffuse infection involving the dermis and subcutaneous tissues (Fig. 3). Early-phase cellulitis generally does not present with an abscess; however, abscesses may form over time. Patients typically report a history of pain, erythema, and swelling of the symptomatic area50. Cellulitis is a clinical diagnosis, and imaging is not required to make the diagnosis; imaging studies can indicate the extent of infection54. On computed tomography (CT), cellulitis presents with soft-tissue thickening and swelling, fat stranding, and enhancement on contrast-enhanced imaging. Subcutaneous emphysema without penetrating trauma suggests necrotizing fasciitis50,54. Magnetic resonance imaging (MRI) has been shown to be effective at differentiating among cellulitis, necrotizing fasciitis, and osteomyelitis, particularly in high-risk patient populations54. Imaging should not be obtained in patients with clear clinical evidence of cellulitis or necrotizing fasciitis.

The treatment of cellulitis is nonsurgical and is centered around antibiotic therapy against the most likely organism, typically S. aureus or Streptococcus species (Table I). Patients should be reevaluated after 24 to 48 hours of antibiotic therapy to assess clinical response55; most respond to therapy within 5 to 10 days50. Antibiotics should be continued for approximately 3 days after the acute inflammation has subsided to ensure that the infection has been treated adequately50.

\section{Subcutaneous Abscess}

A subcutaneous abscess is a purulent softtissue infection that generally follows a puncture injury or wound5. The most common pathogen is $S$. aureus5. The diagnosis is typically clinical, based on physical examination findings and patient history. A subcutaneous abscess generally presents with a central fluctuant area surrounded by cellulitis5. Because of the superficial nature of the infection, imaging is generally not necessary. 
Publication: JBJS Reviews

Type: Review Article; Volume: ; Issue:

However, imaging in the form of ultrasonography

or MRI can be of value in equivocal cases 28.

Treatment of a subcutaneous abscess consists of incision and drainage, followed by empiric antibiotic treatment (Table I) until wound culture specimens specify the causative agent and culturespecific antibiotics can be administered5,56. Current guidelines recommend antibiotic therapy for 7 to 14 days, with the final treatment duration depending on the clinical response to the regimen7,23.

\section{Deep Space Infections/Abscesses}

Deep space infections of the hand occur in the thenar space, the midpalmar space, the hypothenar space, the space of Parona, the dorsal subcutaneous and subaponeurotic spaces, and web spaces2,4-9. Determination of the specific infected location is essential as it drives surgical planning. These infections make up $2 \%$ of all cases of hand infection8,9. They are generally caused by direct inoculation (i.e., penetrating injury) or contiguous spread from nearby structures (i.e., septic FTS)2,5-7. Presentations vary depending on the exact location of the infection. The most common pathogens are the normal skin flora, specifically Staphylococcus and Streptococcus species2,3,8,10,11.

The diagnosis of deep space infections is based on the physical examination in combination with imaging. CT and ultrasound may indicate fluid collections but have been shown to be inconsistent. MRI has good sensitivity and specificity for deep space infections and is very effective at discriminating the location of the infection; therefore, if expeditiously available, MRI should be used to guide treatment 4 .

Typically, deep space infections present with localized erythema, swelling, pain, and possibly fluctuance (Fig. 4). Depending on the specific location of the infection, additional signs may be present on physical examination. For example, thenar infections typically present with the thumb abducted, pain on active extension and opposition, and possible involvement of the first web space $2,4,5,8$. In contrast, infections of the midpalmar (or deep palmar) regions are bound by the metacarpals and the palmar aponeurosis. Therefore, these patients present with painful 
Publication: JBJS Reviews

Type: Review Article; Volume: ; Issue:

erythematous swelling on both the palmar and dorsal surfaces of the hand, resulting in a loss of concavity of the palm. They also experience tenderness on active and passive movement of the digits2,5,6,8. Hypothenar infections are infrequent and present with inflammation and swelling of the ulnar border of the hand. Patients will typically present with the fifth digit abducted to maximize the volume of the compartment6,8. Infection of the space of Parona may spread to or from the radial or ulnar bursae since they communicate with each other. In general, swelling is diffuse, and patients will present with pain on flexion of the digits and wrist extension. The swelling also may compress the median nerve, causing an acute carpal tunnel syndrome2,5,8. Lastly, a web space infection also is known as a "collar button abscess" because of its hourglass configuration that spreads peripherally at both the dorsal and palmar ends but remains narrow in the middle while presenting with signs of both palmar and dorsal inflammation. Typically, digits on either side of the affected web are abducted to maximize its volume2,4-6,8.

Treatment for all deep space infections of the hand consists of incision and drainage of the affected structures and areas. Empiric antibiotics (Table I) should be administered until operative culture specimens specify the causative agent and culture-specific antibiotics can be initiated.

\section{Animal Bites}

The most common bite injuries of the hand are from dogs, followed by those from cats57-60. Dog and cat bites are the cause of $1 \%$ of all emergency room visits in the United States59. Cat bites are more common in women and the elderly, whereas dog bites are more common among young children (5 to 9 years old), most likely because of their small size and lack of insight about provocative behavior that could agitate a dog59. Generally, the animal is known to the victim58.

Studies have shown that cat bites have a higher risk of infection (up to 2 times greater) than dog bites58-60. Bites resulting from dogs are comparatively shallow and more crushing in nature59-61. This is in contrast to cat bites, where their sharp teeth result in lacerations with deeper 
Publication: JBJS Reviews

Type: Review Article; Volume: ; Issue:

penetration and direct tissue inoculation57-60,62,63. Common complications resulting from animal bite infections include cellulitis (Fig. 3), osteomyelitis, septic arthritis, tenosynovitis, lymphangitis, and local abscess57,59-63. Immunocompromised individuals are at increased risk of the common complications that are mentioned above in addition to some uncommon complications: endocarditis, meningitis, brain abscess, and sepsis59,60,63.

The most common pathogens in dog and cat bites are Staphylococcus, Pasteurella, and Streptococcus species57,59-63. However, polymicrobial infections are common with all animal bites.

Patients will typically present with lacerations and/or puncture wounds to their hand and a history that is noteworthy for an animal bite. Specific clinical presentation depends on the animal that bit the patient and the pathogen. Patients presenting at $>8$ hours after the bite have significantly higher rates of infection59,60. Animal bite infections may progress rapidly due to direct inoculation of the wound, with classic signs including erythema, swelling, fluctuance, and drainage (Fig. 3). Patients also may present with local or proximal lymphadenitis and/or lymphangitis.

Acquiring culture specimens from the site of the animal bite is recommended because of their polymicrobial nature. The management of animal bites should always begin with empiric antibiotics. For deep and/or fluctuant wounds, surgical exploration, culture, and debridement may be necessary. Prompt cleaning of the bite wound can significantly reduce the risk of infection and rabies transmission59,60.

Empiric antibiotics should adequately cover the most likely pathogens: Staphylococcus, Pasteurella, and Streptococcus species (Table I)57,5963. Empiric antibiotics should be administered until culture specimens specify the causative agent and culture-specific antibiotics can be initiated 64. If the rabies vaccination status of the animal is unknown, one should consider administering the human diploid vaccination series for rabies prophylaxis and/or, depending on the exposure risk and the 
Publication: JBJS Reviews

Type: Review Article; Volume: ; Issue:

behavior of the animal, rabies immunoglobulin also should be administered59,60.

\section{Human Bites}

Human bites are a relatively uncommon

cause of hand bite injuries, accounting for $2 \%$ of all hand bite cases57,59. The most common manifestation of these injuries is a closed-fist injury due to fighting when the dorsal surface of the hand contacts teeth, causing lacerations, commonly over the metacarpophalangeal joints57. A variety of anaerobes and aerobes may colonize a human bite wound, with the most common pathogens being those that form the natural flora of the mouth, including Streptococcus pyogenes, S. aureus, Eikenella corrodens, and Corynebacterium species57,64,65.

Typically, human bite wounds and infections present as isolated injuries, often centered around the metacarpophalangeal joint from the teeth lacerating the patient's clenched hand57,64 (Fig. 5). The wound and/or laceration may appear minor, but the wound should be carefully examined as penetration of deeper structures, including the extensor mechanism and the metacarpophalangeal joint capsule, is not uncommon57. Additionally, radiographs are indicated to evaluate for fractures, articular defects, or foreign bodies centered around the bite wound and the associated metacarpophalangeal joint57,64.

Human bite wound infections, even if appropriately treated, may progress rapidly due to direct inoculation of the site by oral flora64. Classic signs of infection, including pain, erythema, swelling, fluctuance, and drainage, may develop at 24 to 72 hours after the bite64. Patients also may present with local lymphadenopathy, reducing the range of motion of nearby joints64. Acquiring culture specimens from the site of the bite wound is recommended because of the polymicrobial nature of bite wounds. The management of human bites should always include empiric antibiotic management (Table I). For deep and complex human bite wounds, surgical intervention is indicated to explore the wound, obtain culture specimens, and debride and irrigate the wound. 


\section{Fungal Infections}

Fungal infections of the hand are rare and typically present in immunocompromised individuals66. These infections are categorized as cutaneous, subcutaneous, deep, and systemic infections2,5,67. Risk factors for fungal infections of the hand include immunocompromised states, chronic wounds, and sites of persistent moisture8,41,66-68. Because of their low prevalence, most of the data available regarding the epidemiology, diagnosis, and treatment of fungal infections are based on case reports, small series, and expert opinion66. Unlike bacterial infections, fungal infections of the hand tend to be less tender, lack drainage, and are insidious.

Superficial/cutaneous fungal infections are the most common fungal infection of the hand and typically involve the glabrous skin (tinea corporis) and the palms (tinea manuum), with the nails (onychomycosis) being the most common site $2,5,41,67$. Onychomycosis typically presents with nail overgrowth/irregularities and surrounding reddened and cracked skin2,67. Candida albicans and other dermatophytes are the most common cause of cutaneous and nail fungal infections41,67. The causative pathogen can typically be identified using fungal cultures and potassium hydroxide $(\mathrm{KOH})$ preparations2,5,41,67. The preferred treatment for simple infections is topical antifungals (e.g., efinaconazole, amorolfine, tavaborole, or ciclopirox)2,5,41. If initial therapy with a topical antifungal fails to resolve the infection, then oral antifungals (e.g., terbinafine, griseofulvin, ketoconazole, fluconazole, or itraconazole) can be initiated. Overall, nail-related fungal infections are historically difficult to cure, with rates ranging from $57 \%$ to $80 \%$, irrespective of the choice of antifungal medication, and may require nail removal to eradicate the fungal infection2,5,67.

A subcutaneous infection involves seeding of the subcutaneous tissues by fungal spores. This may result in a granulomatous infection with a primary ulcerative lesion and secondary regional lymphadenopathy. Sporotrichosis, also known as "rose thorn disease," is the most common subcutaneous fungal infection of the hand. Other 
Publication: JBJS Reviews

Type: Review Article; Volume: ; Issue:

less common fungal pathogens include histoplasmosis, blastomycosis, cryptococcus, and coccidioidomycosis; the risk of these infections is based on exposure history2,5,41,67. These organisms can be identified via fungal cultures66. The preferred antifungal treatment is echinocandins (e.g., caspofungin), triazoles (e.g., voriconazole, itraconazole), or amphotericin $\mathrm{B}_{2,41,66,67 \text {. }}$

Deep and systemic fungal infections are rare and are caused by organisms that are either virulent (histoplasmosis, blastomycosis, coccidioidomycosis) or opportunistic (mucormycosis, aspergillosis, Candida species). These infections typically present in immunocompromised patients and spread hematogenously. Deep fungal infections will require surgical intervention in the form of incision and debridement with concurrent systemic antifungals such as amphotericin B, itraconazole, or ketoconazole2,5,41,66.

Overview

Patients presenting with hand infections may be treated effectively by observing the principles of prompt diagnosis, followed by judiciously prescribed antibiotics and surgical management when indicated. 
Publication: JBJS Reviews

Type: Review Article; Volume: ; Issue:

\section{References}

1. Downs DJ, Wongworawat MD, Gregorius SF. Timeliness of appropriate antibiotics in hand infections. Clin Orthop Relat Res. 2007; Aug;461:17-9.

2. Franko OI, Abrams RA. Hand infections. Orthop Clin North Am. 2013 Oct;44(4):625-34.

3. Houshian S, Seyedipour S, Wedderkopp N. Epidemiology of bacterial hand infections. Int J Infect Dis. 2006 Jul;10(4):315-9. Epub 2006 Feb 17.

4. Koshy JC, Bell B. Hand Infections. J Hand Surg Am. 2019 Jan;44(1):46-54. Epub 2018 Jul 14.

5. McDonald LS, Bavaro MF, Hofmeister EP, Kroonen LT. Hand infections. J Hand Surg Am. 2011 Aug;36(8):1403-12.

6. Ong YS, Levin LS. Hand infections. Plast Reconstr Surg. 2009 Oct;124(4):225e-33e.

7. Osterman M, Draeger R, Stern P. Acute hand infections. J Hand Surg Am. 2014 Aug;39(8):1628-35; quiz 1635.

8. Thornton DJA, Lindau T. (iii) Hand infections. Orthop Trauma. 2010 Jun;24(3):186-96.

9. Warbrick-Smith J, Smith J. Acute infections of the hand. InnovAiT. 2013;6(11):688-93.

10. Fowler JR, Ilyas AM. Epidemiology of adult acute hand infections at an urban medical center. J Hand Surg Am. 2013 Jun;38(6):1189-93. Epub 2013 May 3.

11. Gottschalk HP, Mezera K, Golden AS, Reisch JS. Communityacquired methicillin resistant Staphylococcus aureus infections of the hand. Curr Orthop Pract. 2011 Jan/Feb;22(1):59-63.

12. Fowler JR, Greenhill D, Schaffer AA, Thoder JJ, Ilyas AM. Evolving incidence of MRSA in urban hand infections. Orthopedics. 2013 Jun;36(6):796-800.

13. Tosti R, Samuelsen BT, Bender S, Fowler JR, Gaughan J, Schaffer AA, Ilyas AM. Emerging multidrug resistance of methicillin-resistant Staphylococcus aureus in hand infections. J Bone Joint Surg Am. 2014 Sep 17;96(18):1535-40.

14. Kistler JM, Vroome CM, Ramsey FV, Ilyas AM. Increasing multidrug antibiotic resistance in MRSA infections of the hand: a 10-year analysis of risk factors. Hand (N Y). 2019 Mar 22;155894471983769(March):1558944719837693. Epub 2019 Mar 22.

15. Kiran RV, McCampbell B, Angeles AP, Montilla RD, Medina C, Mitra A, Gaughn J, Spears J, Mitra A. Increased prevalence of community-acquired methicillin-resistant Staphylococcus aureus in hand infections at an urban medical center. Plast Reconstr Surg. 2006 Jul;118(1):161-6, discussion 167-9.

16. LeBlanc DM, Reece EM, Horton JB, Janis JE. Increasing incidence of methicillin-resistant Staphylococcus aureus in hand infections: a 3-year county hospital experience. Plast Reconstr Surg. 2007 Mar;119(3):935-40.

17. Bach HG, Steffin B, Chhadia AM, Kovachevich R, Gonzalez $\mathrm{MH}$. Community-associated methicillin-resistant Staphylococcus aureus hand infections in an urban setting. J Hand Surg Am. 2007 Mar;32(3):380-3.

18. O’Malley M, Fowler J, Ilyas AM. Community-acquired methicillin-resistant Staphylococcus aureus infections of the hand: prevalence and timeliness of treatment. J Hand Surg Am. 2009 Mar;34(3):504-8.

19. Tosti R, Ilyas AM. Empiric antibiotics for acute infections of the hand. J Hand Surg Am. 2010 Jan;35(1):125-8. 


\section{Publication: JBJS Reviews \\ Type: Review Article; Volume: ; Issue:}

20. Weinzweig N, Gonzalez M. Surgical infections of the hand and upper extremity: a county hospital experience. Ann Plast Surg. 2002 Dec;49(6):621-7.

21. Gorwitz RJ, Jernigan DB, Powers JH, Jernigan JA. Strategies for clinical management of MRSA in the community: summary of an experts' meeting convened by the Centers for Disease Control and Prevention. 2006 Mar. Accessed 2020 Feb 11. https://www.cdc.gov/mrsa/pdf/MRSAStrategies-ExpMtgSummary-2006.pdf

22. Bhatnagar R, Milchteim C, Barth R, Gunther SF. Incidence and treatment of methicillin-resistant Staphylococcus aureus in hand infections presenting in an urban setting. Curr Orthop Pract. 2012 Mar/Apr;23(2):130-2.

23. Amin AN, Cerceo EA, Deitelzweig SB, Pile JC, Rosenberg DJ, Sherman BM. Hospitalist perspective on the treatment of skin and soft tissue infections. Mayo Clin Proc. 2014 Oct;89(10):1436-51. Epub 2014 Jun 25.

24. Tosti R, Trionfo A, Gaughan J, Ilyas AM. Risk factors associated with clindamycin-resistant, methicillin-resistant Staphylococcus aureus in hand abscesses. J Hand Surg Am. 2015 Apr;40(4):673-6. Epub 2015 Feb 21.

25. Kameyama M, Meguro S, Funae O, Atsumi Y, Ikegami H. The presence of limited joint mobility is significantly associated with multiple digit involvement by stenosing flexor tenosynovitis in diabetics. J Rheumatol. 2009 Aug;36(8):1686-90. Epub 2009 Jun 16.

26. Gordon RJ, Lowy FD. Bacterial infections in drug users. N Engl J Med. 2005 Nov 3;353(18):1945-54.

27. Del Giudice P. Cutaneous complications of intravenous drug abuse. Br J Dermatol. 2004 Jan;150(1):1-10.

28. Leggit JC. Acute and chronic paronychia. Am Fam Physician. 2017 Jul 1;96(1):44-51.

29. Rockwell PG. Acute and chronic paronychia. Am Fam Physician. 2001 Mar 15;63(6):1113-6.

30. Shafritz AB, Coppage JM. Acute and chronic paronychia of the hand. J Am Acad Orthop Surg. 2014 Mar;22(3):165-74.

31. Jinnouchi O, Kuwahara T, Ishida S, Okano Y, Kasei Y, Kunitomo K, Takeda N. Anti-microbial and therapeutic effects of modified Burow's solution on refractory otorrhea. Auris Nasus Larynx. 2012 Aug;39(4):374-7. Epub 2011 Aug 20.

32. Wollina U. Acute paronychia: comparative treatment with topical antibiotic alone or in combination with corticosteroid. J Eur Acad Dermatol Venereol. 2001 Jan;15(1):82-4.

33. Tosti A, Piraccini BM, Ghetti E, Colombo MD. Topical steroids versus systemic antifungals in the treatment of chronic paronychia: an open, randomized double-blind and double dummy study. J Am Acad Dermatol. 2002 Jul;47(1):73-6.

34. Rigopoulos D, Gregoriou S, Belyayeva E, Larios G, Kontochristopoulos G, Katsambas A. Efficacy and safety of tacrolimus ointment $0.1 \%$ vs. betamethasone 17 -valerate $0.1 \%$ in the treatment of chronic paronychia: an unblinded randomized study. Br J Dermatol. 2009 Apr;160(4):858-60. Epub 2008 Dec 16.

35. Okano M, Noguchi S, Tabata K, Matsumoto Y. Topical gentian violet for cutaneous infection and nasal carriage with MRSA. Int J Dermatol. 2000 Dec;39(12):942-4.

36. Merritt W. The impecunious treatment for chronic paronychia and ingrown fingernails: back to the future. Presented as a poster exhibit at the Annual Meeting of the American Association for Hand Surgery; 2013 Jan 9-12; Naples, FL. 


\section{Publication: JBJS Reviews \\ Type: Review Article; Volume: ; Issue:}

Accessed 2020 Feb 11.

https://meeting.handsurgery.org/abstracts/2013/P64.cgi

37. Pabari A, Iyer S, Khoo CT. Swiss roll technique for treatment of paronychia. Tech Hand Up Extrem Surg. 2011 Jun;15(2):75-7.

38. Tannan SC, Deal DN. Diagnosis and management of the acute felon: evidence-based review. J Hand Surg Am. 2012 Dec;37(12):2603-4.

39. Rubright JH, Shafritz AB. The herpetic whitlow. J Hand Surg Am. 2011 Feb;36(2):340-2. Epub 2010 Dec 24.

40. Wu IB, Schwartz RA. Herpetic whitlow. Cutis. 2007 Mar;79(3):193-6.

41. Chan E, Bagg M. Atypical hand infections. Orthop Clin North Am. 2017 Apr;48(2):229-40. Epub 2017 Feb 1.

42. Draeger RW, Bynum DK Jr. Flexor tendon sheath infections of the hand. J Am Acad Orthop Surg. 2012 Jun;20(6):373-82.

43. Giladi AM, Malay S, Chung KC. A systematic review of the management of acute pyogenic flexor tenosynovitis. J Hand Surg Eur Vol. 2015 Sep;40(7):720-8. Epub 2015 Feb 10.

44. Pang HN, Teoh LC, Yam AKT, Lee JYL, Puhaindran ME, Tan $\mathrm{ABH}$. Factors affecting the prognosis of pyogenic flexor tenosynovitis. J Bone Joint Surg Am. 2007 Aug;89(8):1742-8.

45. Hyatt BT, Bagg MR. Flexor tenosynovitis. Orthop Clin North Am. 2017 Apr;48(2):217-27.

46. Kennedy CD, Huang JI, Hanel DP. In brief: Kanavel's signs and pyogenic flexor tenosynovitis. Clin Orthop Relat Res. 2016 Jan;474(1):280-4. Epub 2015 May 29.

47. Dailiana ZH, Rigopoulos N, Varitimidis S, Hantes M, Bargiotas K, Malizos KN. Purulent flexor tenosynovitis: factors influencing the functional outcome. J Hand Surg Eur Vol. 2008 Jun;33(3):280-5.

48. DiPasquale AM, Krauss EM, Simpson A, Mckee DE, Lalonde DH. Cases of early infectious flexor tenosynovitis treated non-surgically with antibiotics, immobilization, and elevation. Plast Surg (Oakv). 2017 Nov;25(4):272-4. Epub 2017 Sep 27.

49. Ketonis C, Hickock NJ, Ilyas AM. Rethinking pyogenic flexor tenosynovitis: biofilm formation treated in a cadaveric model. J Hand Microsurg. 2017 Dec;9(3):131-8. Epub 2017 Nov 27.

50. Gunderson CG. Cellulitis: definition, etiology, and clinical features. Am J Med. 2011 Dec;124(12):1113-22. Epub 2011 Oct 18.

51. Volz KA, Canham L, Kaplan E, Sanchez LD, Shapiro NI, Grossman SA. Identifying patients with cellulitis who are likely to require inpatient admission after a stay in an ED observation unit. Am J Emerg Med. 2013 Feb;31(2):360-4. Epub 2012 Nov 15.

52. Chung MT, Wilson P, Rinker B. Community-acquired methicillin-resistant Staphylococcus aureus hand infections in the pediatric population. J Hand Surg Am. 2012 Feb;37(2):326-31. Epub 2011 Dec 21.

53. Chira S, Miller LG. Staphylococcus aureus is the most common identified cause of cellulitis: a systematic review. Epidemiol Infect. 2010 Mar;138(3):313-7. Epub 2009 Aug 3.

54. Chaudhry AA, Baker KS, Gould ES, Gupta R. Necrotizing fasciitis and its mimics: what radiologists need to know. AJR Am J Roentgenol. 2015 Jan;204(1):128-39.

55. Stevens DL, Bisno AL, Chambers HF, Dellinger EP, Goldstein EJ, Gorbach SL, Hirschmann JV, Kaplan SL, Montoya JG, 


\section{Publication: JBJS Reviews \\ Type: Review Article; Volume: ; Issue:}

Wade JC; Infectious Diseases Society of America. Practice guidelines for the diagnosis and management of skin and soft tissue infections: 2014 update by the Infectious Diseases Society of America. Clin Infect Dis. 2014 Jul 15;59(2):e10-52. Erratum in: Clin Infect Dis. 2015 May $1 ; 60(9): 1448$.

56. Spellberg B, Boucher H, Bradley J, Das A, Talbot G. To treat or not to treat: adjunctive antibiotics for uncomplicated abscesses. Ann Emerg Med. 2011 Feb;57(2):183-5.

57. Raval P, Khan W, Haddad B, Mahapatra AN. Bite injuries to the hand - review of the literature. Open Orthop J. 2014 Jun 27;8(1):204-8.

58. Benson LS, Edwards SL, Schiff AP, Williams CS, Visotsky JL. Dog and cat bites to the hand: treatment and cost assessment. J Hand Surg Am. 2006 Mar;31(3):468-73.

59. Oehler RL, Velez AP, Mizrachi M, Lamarche J, Gompf S. Biterelated and septic syndromes caused by cats and dogs. Lancet Infect Dis. 2009 Jul;9(7):439-47.

60. Jha $S$, Khan WS, Siddiqui NA. Mammalian bite injuries to the hand and their management. Open Orthop J. 2014 Jun 27;8(1):194-8.

61. Nygaard M, Dahlin LB. Dog bite injuries to the hand. J Plast Surg Hand Surg. 2011 Apr;45(2):96-101.

62. Kwo S, Agarwal JP, Meletiou S. Current treatment of cat bites to the hand and wrist. J Hand Surg Am. 2011 Jan;36(1):152-3. Epub 2009 Dec 14.

63. Babovic N, Cayci C, Carlsen BT. Cat bite infections of the hand: assessment of morbidity and predictors of severe infection. J Hand Surg Am. 2014 Feb;39(2):286-90.

64. Brook I. Management of human and animal bite wounds: an overview. Adv Skin Wound Care. 2005 May;18(4):197203.

65. Shoji K, Cavanaugh Z, Rodner CM. Acute fight bite. J Hand Surg Am. 2013 Aug;38(8):1612-4. Epub 2013 May 6.

66. Amirtharajah M, Lattanza L. Fungal infections of the hand. Curr Orthop Pract. 2010 Nov;21(6):564-7.

67. Eo S, Jones NF. Fungal infections of the hand and upper extremity. J Am Soc Surg Hand. 2004 Nov;4(4):250-5.

68. O'Shaughnessy MA, Tande AJ, Vasoo S, Enzler MJ, Berbari EF, Shin AY. A rare diagnosis: recognizing and managing fungal tenosynovitis of the hand and upper extremity. J Hand Surg Am. 2017 Feb;42(2):e77-89. Epub 2016 Dec 20. 
Publication: JBJS Reviews

Type: Review Article; Volume: ; Issue:

Fig. 1

Acute paronychia. Note the fluctuance and

erythema around the nail fold.

Fig. 2

Septic flexor tenosynovitis. Note the swelling, erythema, and flexed posture of the finger. As this is a long-standing case, there is also fluctuance.

Fig. 3

Cellulitis of the dorsum of the hand from a cat bite. Note the erythema and edema in the subcutaneous tissue.

Fig. 4

Deep space infection. Note the swelling, erythema, and fluctuance emanating deep to the thenar musculature.

Fig. 5

Human fight bite. Note the dorsal laceration and swelling over the metacarpophalangeal joint. As this is a late-presenting case, note the abduction of the joint from the secondary septic joint development and/or the collar button abscess formation. 
Publication: JBJS Reviews

Type: Review Article; Volume: ; Issue:

TABLE I Initial Antibiotic Therapy Recommendations

\begin{tabular}{|c|c|c|c|}
\hline \multirow[b]{2}{*}{ Infection } & \multirow[b]{2}{*}{ Most Likely Organisms } & \multicolumn{2}{|c|}{ Antibiotic Therapy } \\
\hline & & Intravenous & Oral \\
\hline Cellulitis & $\begin{array}{l}\text { Staphylococcus aureus } \\
\text { Streptococcus species }\end{array}$ & $\begin{array}{l}\text { Vancomycin } \\
\text { Clindamycin }\end{array}$ & $\begin{array}{l}\text { Doxycycline } \\
\text { Trimethoprim/sulfamethoxazole } \\
\text { Clindamycin }\end{array}$ \\
\hline Felon & $\begin{array}{l}\text { Staphylococcus aureus } \\
\text { Streptococcus species }\end{array}$ & $\begin{array}{l}\text { Vancomycin } \\
\text { Clindamycin }\end{array}$ & $\begin{array}{l}\text { Doxycycline } \\
\text { Trimethoprim/sulfamethoxazole } \\
\text { Clindamycin }\end{array}$ \\
\hline Paronychia & $\begin{array}{l}\text { Staphylococcus aureus } \\
\text { Streptococcus species } \\
\text { Pseudomonas species }\end{array}$ & $\begin{array}{l}\text { Vancomycin } \\
\text { Clindamycin }\end{array}$ & $\begin{array}{l}\text { Doxycycline } \\
\text { Trimethoprim/sulfamethoxazole } \\
\text { Clindamycin } \\
\text { Ciprofloxacin }\end{array}$ \\
\hline Flexor tenosynovitis & $\begin{array}{l}\text { Staphylococcus aureus } \\
\text { Streptococcus species }\end{array}$ & $\begin{array}{l}\text { Vancomycin } \\
\text { Clindamycin }\end{array}$ & $\begin{array}{l}\text { Doxycycline } \\
\text { Trimethoprim/sulfamethoxazole } \\
\text { Clindamycin } \\
\text { Ciprofloxacin }\end{array}$ \\
\hline Subcutaneous abscess & $\begin{array}{l}\text { Staphylococcus aureus } \\
\text { Streptococcus species }\end{array}$ & $\begin{array}{l}\text { Vancomycin } \\
\text { Clindamycin }\end{array}$ & $\begin{array}{l}\text { Doxycycline } \\
\text { Trimethoprim/sulfamethoxazole } \\
\text { Clindamycin }\end{array}$ \\
\hline Deep space abscess & $\begin{array}{l}\text { Staphylococcus aureus } \\
\text { Streptococcus species }\end{array}$ & $\begin{array}{l}\text { Vancomycin } \\
\text { Clindamycin }\end{array}$ & $\begin{array}{l}\text { Doxycycline } \\
\text { Trimethoprim/sulfamethoxazole } \\
\text { Clindamycin }\end{array}$ \\
\hline Human bite & $\begin{array}{l}\text { Staphylococcus species } \\
\text { Streptococcus species } \\
\text { Eikenella species } \\
\text { Corynebacterium species }\end{array}$ & $\begin{array}{l}\text { Ampicillin/sulbactam } \\
\text { Clindamycin } \\
\text { Ciprofloxacin }\end{array}$ & $\begin{array}{l}\text { Amoxicillin/clavulanate } \\
\text { Clindamycin } \\
\text { Ciprofloxacin }\end{array}$ \\
\hline Animal bite & $\begin{array}{l}\text { Staphylococcus species } \\
\text { Streptococcus species } \\
\text { Pasteurella multocida }\end{array}$ & $\begin{array}{l}\text { Ampicillin/sulbactam } \\
\text { Clindamycin } \\
\text { Ciprofloxacin }\end{array}$ & $\begin{array}{l}\text { Amoxicillin/clavulanate } \\
\text { Clindamycin } \\
\text { Ciprofloxacin }\end{array}$ \\
\hline Herpetic whitlow & Herpes simplex virus & Acyclovir & Acyclovir \\
\hline
\end{tabular}




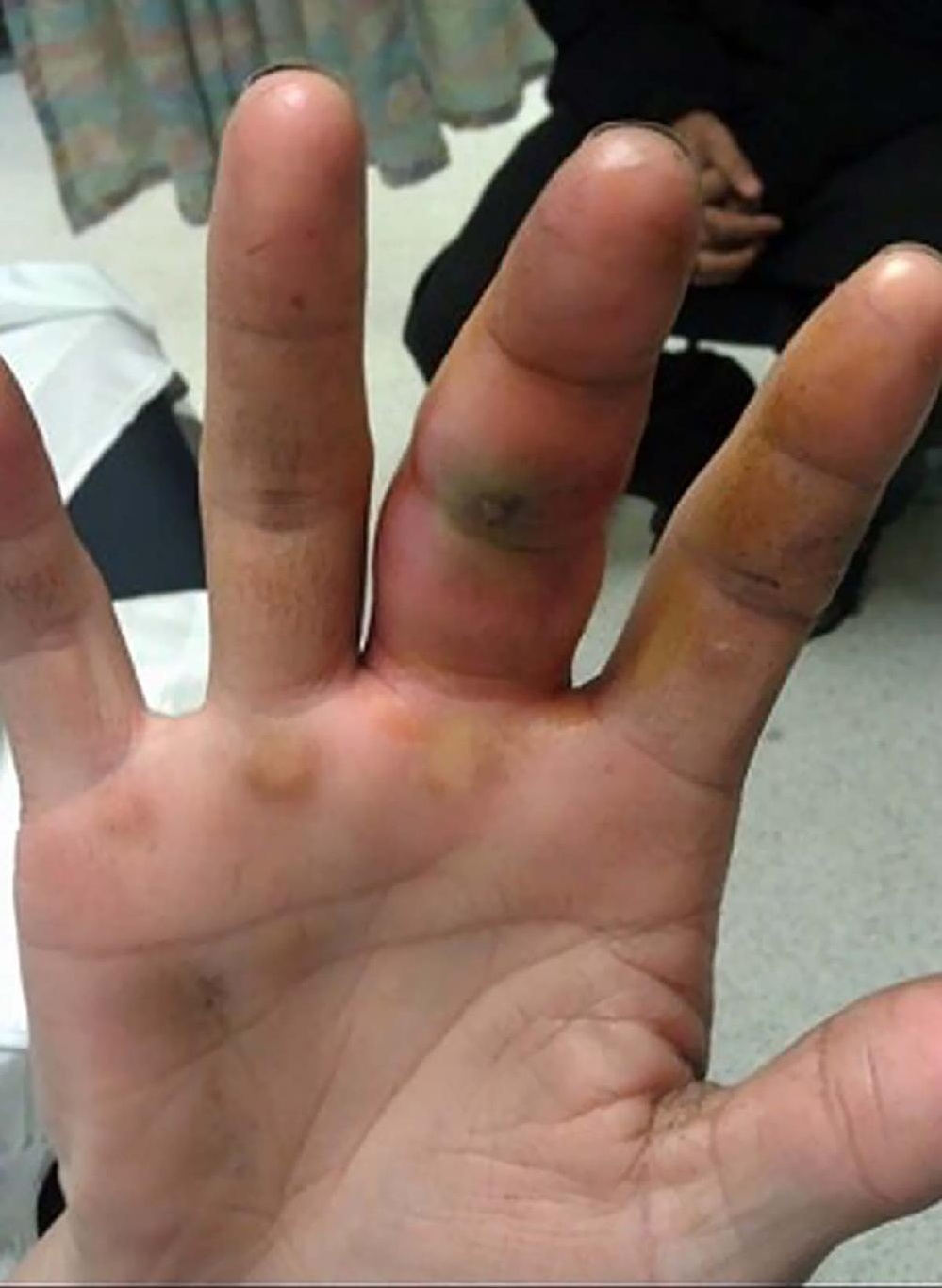









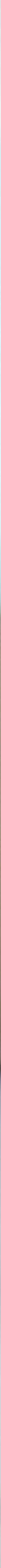




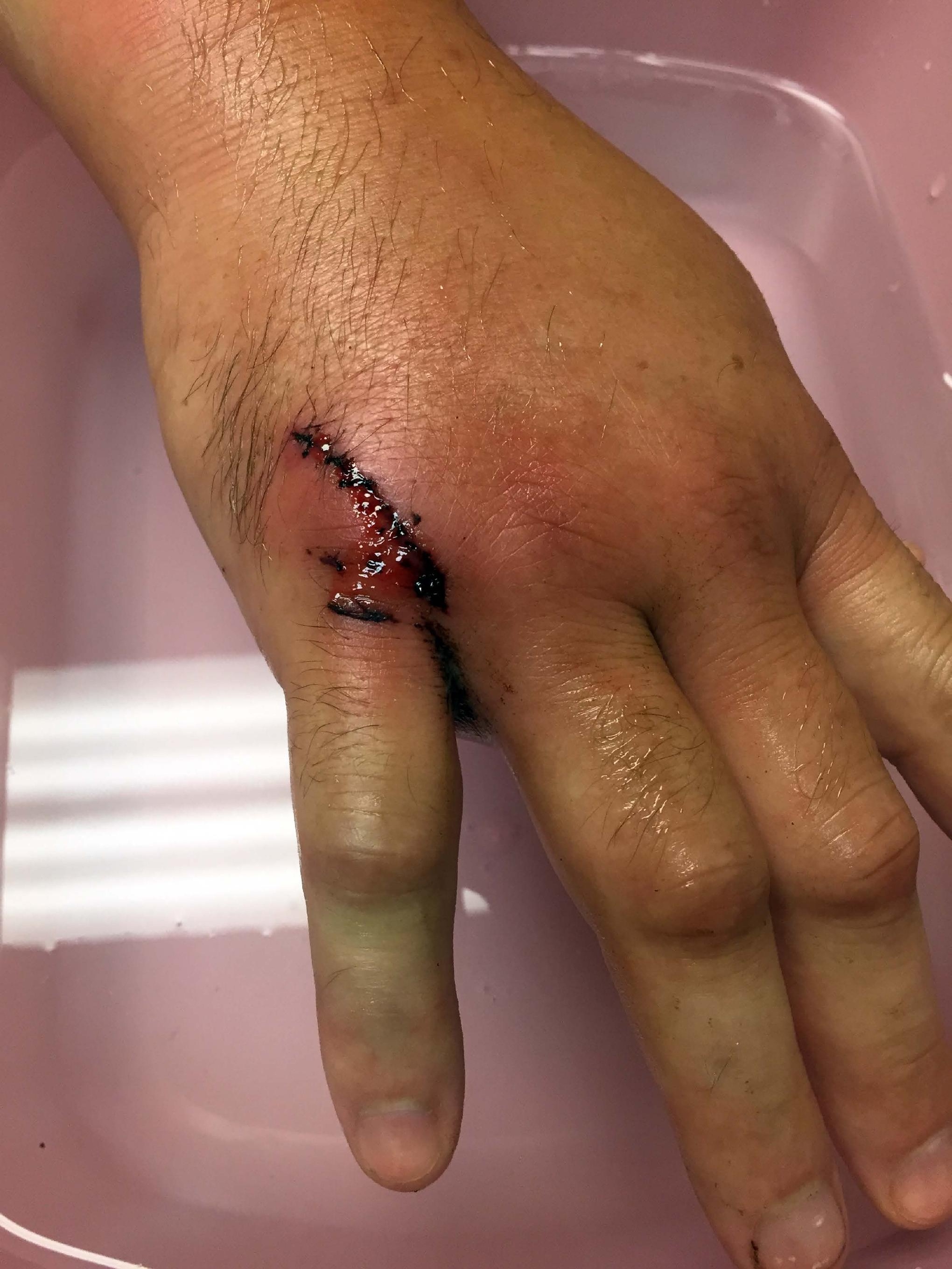

